\title{
It's How You Say It
}

\section{Using Value-Based Language for Elevator Speech Awesomeness}

\author{
JENNA NEMEC-LOISE
}

Everyday Advocacy empowers ALSC members to embrace their roles as library advocates by focusing on their daily efforts to serve youth and families. Each lighthearted column features easy-to-implement strategies and techniques for asserting the transformative power of libraries both within communities and beyond them. Contact Jenna Nemec-Loise at everyday-advocacy @hotmail.com with comments and ideas for future topics.

If we're going to be colleagues and friends, you should probably know these three things about me:

1. I think Everyday Advocacy is rad and won't rest until everyone else thinks so, too;

2. "Awesome" is pretty much my favorite word ever; and

3. It pains me to admit when my mom's right about something.

Now I love my mom. She's a neat lady. But when I hear myself parroting things she told me when I was a surly tween and teen? $\mathrm{Oh}$, man. We must be on the verge of a new world order.

Well, Everyday Advocates, I'm here to tell you change is a-comin because Kathy Nemec was definitely onto something with this 1980s Mom-ism: "It's not so much what you say. It's how you say it."

Of course, my mom was talking about my affinity for sarcasm. (The fierce words, "Watch your tone, young lady!" usually followed.)

But that doesn't mean we can't channel my mom when we think about crafting impactful library messages for policymakers and community stakeholders.
Maybe a little Kathy Nemec is exactly what we need.

With National Library Legislative Day right around the corner, it's time to write elevator speeches that articulate the value of what we bring to children, families, and communities through libraries.

How you say it matters, and my mom and I are here to help.

\section{The Skinny on Elevator Speeches}

Do you really need an elevator speech or two? Yes. Yes, you do.

Elevator speeches are brief opportunities-maybe one minute or less-to pique the interest of anyone whose ear you'd like to bend about library-related issues.

When you've got great elevator speeches in your tool kit, you're ready to snap up an Everyday Advocacy opportunity wherever it presents itself-the coffee shop, the park, the alderman's office, or quite naturally, the elevator.

The goal of your elevator speeches shouldn't be to tell listeners everything you want them to know about the library. Instead,

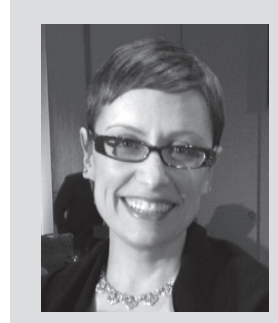

Jenna Nemec-Loise is Member Content Editor, ALSC Everyday Advocacy Website and Electronic Newsletter. 
your speeches should answer the questions, "What do you do, and why is it important?"

Ultimately, you want your listeners to say, “Tell me more!” or ask, "How do you do that?"
Example 3: "I manage a volunteer program at the library."

Example 3 with VBL: "I help kids increase their civic engagement at the library so they can become global citizens who vote on the issues that matter to them."

See the difference? It's pretty hard to ignore.

\section{Using Value-Based Language}

When someone asks what you do as a children's librarian, it might be tempting to respond with the usual litany of responsibilities: storytime, reference, collection development, summer reading, and so on.

But what does that list actually tell your listeners about the value of those critically important activities? Not much-and maybe even nothing at all. That's a scary prospect, right?

By using value-based language (VBL), you can create action-oriented elevator speeches that shift the emphasis away from the programs or services you provide and onto the kids and families you impact. What better way to express how what you do makes a difference and changes lives?

Here's a VBL template for writing awesome elevator speeches:

"I help [insert target audience] [insert verb phrase] at the library so that [insert proven/expected positive outcome for target audience]."

Still clear as mud? Let's try it another way.

Compare the following three sets of examples, each containing a program-centered statement and its VBL counterpart:

Example 1: "I do storytime at the library."

Example 1 with VBL: "I help parents and caregivers promote kindergarten readiness at the library so their young children can start school ready to learn."

Example 2: "I conduct a summer reading program at the library."

Example 2 with VBL: "I help youth and families read, discover, and create at the library so they can become critical thinkers and lifelong learners."

\section{Elevator Speeches in Action}

Every day you're out there creating a better future for children through libraries. Why not let everyone know what you do and why it's important?

As part of the Everyday Advocacy initiative, ALSC is giving away buttons with a call to action at the 2015 ALA Midwinter Meeting and Annual Conference. Attached to each button is a tip sheet created by the Advocacy and Legislation Committee and filled with talking points to help you articulate the value of youth library service.

This spring, we're challenging you to develop your elevator speeches, wear your button proudly, and remind people how you create a better future for children through libraries. What you do matters, and how you say it makes an Everyday Advocacy difference!

I know you've been waiting for just the right moment to get started.

How about now? ¿ 